\title{
Effect of Sintering Temperature on the Grain Size and Mechanical Properties of $\mathrm{Al}_{2} \mathrm{O}_{3}-\mathrm{SiC}$ Nanocomposites
}

\author{
Alireza Moradkhani (10*, Hamidreza Baharvandi**, and Ali Naserifar* \\ *Art \& Architecture Faculty, Yadegar-e Imam Khomeini (RAH) Shahre-Rey Branch, Islamic Azad University, \\ Tehran 15875-1774, Iran \\ **Faculty of Materials \& Manufacturing Processes, Malek-Ashtar University of Technology, Tehran, Iran
}

(Received August 14, 2018; Revised October 10, 2018; Accepted October 10, 2018)

\begin{abstract}
In this research, some mechanical properties of $\mathrm{Al}_{2} \mathrm{O}_{3}$-based composites containing nanoSiC and nanoMgO additives, including elasticity modulus, hardness, and fracture toughness, have been evaluated. Micron-sized $\mathrm{Al}_{2} \mathrm{O}_{3}$ powders containing 0.08 wt.\% nanoMgO particles have been mixed with different volume fractions of nanoSiC particles (2.5 to 15 vol.\%). Untreated samples have been sintered by using hot-press technique at temperatures of 1600 to $1750^{\circ} \mathrm{C}$. The results show significant increases in the mechanical characteristics with increases in the sintering temperature and amount of nanoSiC particles, with the result that the elasticity modulus, hardness, and fracture toughness were obtained as $426 \mathrm{GPa}, 21 \mathrm{GPa}$, and $4.5 \mathrm{MPa} . \mathrm{m}^{1 / 2}$, respectively.
\end{abstract}

Key words : Alumina, Silicon Carbide, Nanocomposite, Sintering Temperature, Mechanical Properties

\section{Introduction}

$\mathrm{A}$ lumina $\left(\mathrm{Al}_{2} \mathrm{O}_{3}\right)$ is an abundant and relatively inexpensive ceramic material that has unique physical and chemical properties. Alumina is one of the oldest types of industrial ceramics that is still prevalent as an industrial material. ${ }^{1)}$ It exhibits two main phases, namely $\alpha$ and $\gamma$. The $\alpha$ phase consists of colorless crystals and crystallizes in hexagonal structure, whereas the $\gamma$ phase is composed of very tiny colourless crystals that exhibit cubic structure and a specific weight of $3.6 \mathrm{~g} / \mathrm{cm}^{3}$. The latter phase transforms to the former phase at high temperatures. The stable phase of alumina is corundum, which exhibits a hexagonal closepacked structure composed of oxygen atoms, in which aluminum atoms occupy two-thirds of the octahedral spaces. ${ }^{2,3)}$ Alumina has significant industrial and commercial importance owing to a wide variety of applications in highstrength materials, bioceramics, microelectronics, coatings, abrasive materials, refractory and reinforcing materials, and catalysts. ${ }^{3,4)}$

In order to enhance the mechanical characteristics of alumina, different additives, including $\mathrm{ZrO}_{2},{ }^{5)} \mathrm{MgO}$, ${ }^{6} \mathrm{Nb}_{2} \mathrm{O}_{5}$, ${ }^{7}$ and $\mathrm{SiC},{ }^{8)}$ can be added to it. Adding $\mathrm{SiC}$ to $\mathrm{Al}_{2} \mathrm{O}_{3}$ in the optimum proportion and the mechanisms involving crack deflection, crack bridging, and phase transformation decrease the grain growth rate and increase the grain boundary strength,

Corresponding author : Alireza Moradkhani

E-mail : moradkhani.a@srbiau.ac.ir

Tel : +989125907184 Fax : +982122935341

ORCID

http://orcid.org/0000-0002-5410-3748 resulting in the mechanical properties being improved in comparison with those of pure alumina. ${ }^{9,10)}$ This composite can be fabricated through common methods, including pressure-off and cold isostatic press or hot press method. Hot press method generally affords the most favorable properties among all the techniques. ${ }^{9,11)}$ Adding only 5 vol.\% nanoSiC to alumina leads to its fracture strength and toughness increasing by 3 and 3.5 times, respectively. Within the sintered and polycrystallized alumina structure, some tensile stress remains at the grain boundaries and in the grains owing to anisotropy in the thermal expansion coefficient and elasticity modulus across different crystallographic directions. In this situation, a crack forms along the grain boundary, with dimensions comparable to that of a grain, owing to the existence of residual stress and defects during the manufacturing process. ${ }^{10,12-14)}$ By sintering alumina at $1500^{\circ} \mathrm{C}$, it is quite possible to achieve a density that is close to the theoretical density. However, after adding 5 vol.\% nanoSiC particles, condensation of the composite becomes more difficult and it is necessary to increase the sintering temperature up to $1700^{\circ} \mathrm{C}$ to achieve full density. If the volume fraction of the particles is increased to 10 vol.\%, the sintering temperature of the composite should be increased to more than $1750^{\circ} \mathrm{C}$ to realize full density. Since $\mathrm{SiC}$ particles do not have sufficient mobility and do not react with $\mathrm{Al}_{2} \mathrm{O}_{3}$ at the sintering temperature, they reduce the mobility of the grain boundaries and, as a result, inhibit the condensation of $\mathrm{Al}_{2} \mathrm{O}_{3}$. Hence, after the addition of $\mathrm{SiC}$ nanopowders, the sintering temperature should increase. ${ }^{10)}$

Scientists have figured out that adding low amounts of $\mathrm{MgO}$ can lead to increased compressibility of $\mathrm{Al}_{2} \mathrm{O}_{3}$, corresponding to the range of the theoretical density. The preva- 
lent theory is that $\mathrm{MgO}$ prevents grain growth by decreasing the grain boundary mobility, which is a result of the formation of a solid solution. Another theory includes accelerated condensation of $\mathrm{Al}_{2} \mathrm{O}_{3}$ upon adding $\mathrm{MgO}$, in which increases in the network permeation coefficients and a decrease in the surface permeation rate are known to be responsible for this phenomenon. ${ }^{15)}$ In addition, adding $\mathrm{MgO}$ to alumina enhances its sintering capability and leads to the fabrication of alumina with a controlled microstructure. ${ }^{16)}$ In $\mathrm{Al}_{2} \mathrm{O}_{3}-\mathrm{SiC}$ nanocomposites, with regard to the presence of $\mathrm{SiC}$ nanoparticles, which reduce the grain boundary mobility, the activated mechanisms that are attributed to the addition of $\mathrm{MgO}$ are more complicated, in contrast to those in pure alumina. ${ }^{17}$

With respect to the fact that some ceramic characteristics such as ballistic performance depend on a number of parameters, including density, porosity, hardness, fracture toughness, elasticity modulus, sonic velocity, mechanical strength, sintering temperature, and microstructural properties, in this study, nanoSiC powders in volume fractions of 0 to 15 vol.\% have been sintered along with micron-sized $\mathrm{Al}_{2} \mathrm{O}_{3}$ powders containing 0.08 wt. $\%$ nanoMgO at temperatures of $1600,1650,1700$, and $1750^{\circ} \mathrm{C}$. The effects of sintering temperature and different combinations of nanoparticle substances on the mechanical characteristics of the fabricated samples, including the density, flexural strength, elasticity modulus, hardness, and fracture toughness, have been investigated, and phase and microstructural analyses of the samples have been performed.

\section{Experimental Procedure}

\subsection{Materials}

The raw materials used for preparing the nanocomposite samples include micronized powder of alumina, silicon carbide nanopowder (nanoSiC), magnesium oxide nanopowder (nanoMgO), isopropanol solution, and argon gas. The alumina powder used had a purity of $99.6 \%$ and its chemical composition is as listed in Table 1; its average size was less than $5 \mu \mathrm{m}$, with the main phase being $\gamma-\mathrm{Al}_{2} \mathrm{O}_{3}$.

Figure 1 reveals the X-ray diffraction (XRD) pattern of the alumina powder, which indicates the presence of $\gamma-\mathrm{Al}_{2} \mathrm{O}_{3}$ phase.

Table 1. Chemical Analysis of Micronized Powder of Primary Alumina

\begin{tabular}{cc}
\hline Material & Weight percent \\
\hline $\mathrm{Al}_{2} \mathrm{O}_{3}$ & $>99.6$ \\
$\mathrm{Na}_{2} \mathrm{O}$ & $<0.1$ \\
$\mathrm{Fe}_{2} \mathrm{O}_{3}$ & $<0.03$ \\
$\mathrm{SiO}_{2}$ & $<0.05$ \\
$\mathrm{TiO}_{2}$ & $<0.005$ \\
$\mathrm{CaO}$ & $<0.05$ \\
$\mathrm{MgO}$ & $<0.1$ \\
\hline
\end{tabular}

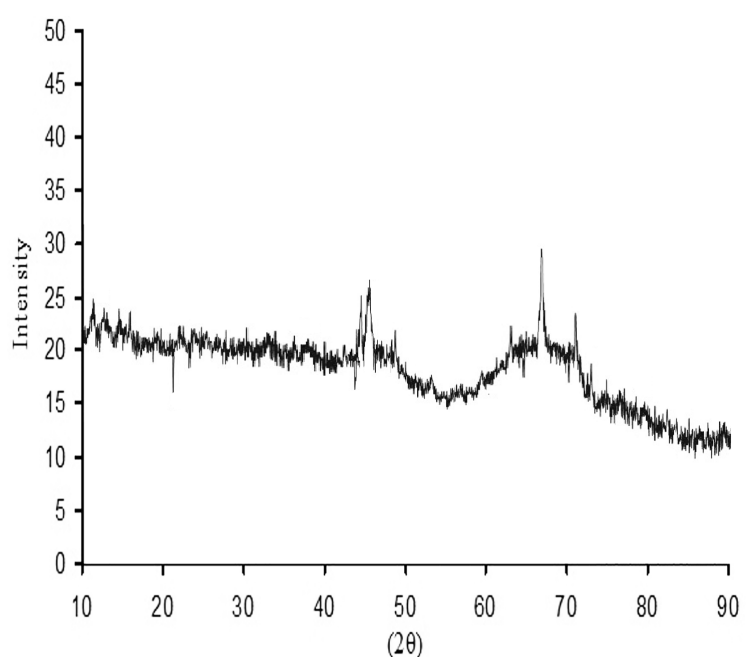

Fig. 1. XRD pattern of the alumina powder.

The microstructural images of the alumina, nanoSiC, and nanoMgO powders obtained by SEM or TEM are shown in Fig. 2, which reveals the existence of particles with the maximum size of roughly $5 \mu \mathrm{m}$ in the $\mathrm{Al}_{2} \mathrm{O}_{3}$ powder. The $\mathrm{SiC}$ nanopowder used in this experiment contains $\alpha$-SiC phase with an average size of $70 \mathrm{~nm}$. The $\mathrm{MgO}$ nanopowder used was obtained by thermal decomposition of ammonium oxalate and magnesium sulfate with particle sizes less than $100 \mathrm{~nm}$, and is a result of the research work of Ahmadzadeh et al.. ${ }^{18)}$ The XRD patterns of nanoSiC and nanoMgO are displayed in Fig. 3.

Isopropanol with the chemical formulation of $\mathrm{C}_{3} \mathrm{H}_{7} \mathrm{OH}$ and purity $99.6 \%$ was used in a ball-mill environment. The argon gas employed was $99.99 \%$ pure, and the results of its chemical analysis are as follows.

$$
\begin{aligned}
\mathrm{O}_{2} & <2 \mathrm{ppm} & \mathrm{H}_{2} \mathrm{O} & <3 \mathrm{ppm} \\
\mathrm{N}_{2} & <0.1 \mathrm{ppm} & \mathrm{C}_{\mathrm{n}} \mathrm{H}_{\mathrm{m}} & <0.1 \mathrm{ppm}
\end{aligned}
$$

The chamber used for the ball-milling is made of stainless steel, with the inner wall composed of 17 tungsten carbide (WC) balls having the diameter of $17 \mathrm{~cm}$. In order to dry out the samples and expedite the evaporation of alcohol over them, a laboratory drier machine manufactured by ElektroWarme-Aachen Co. (model FTK) was used. In order to polish the samples, diamond pastes of variety 30,6 , and $1 \mu \mathrm{m}$ were used. The samples were mounted with a Struers Primopress machine, and Stypex materials were manufactured by Ampco Company at the temperature of $155^{\circ} \mathrm{C}$ by applying a force of $27 \mathrm{KN}$ on the samples. To determine the flexural strengths of the samples, a five-ton machine manufactured by Zwick Company was used at the loading rate of $0.7 \mathrm{~mm} / \mathrm{min}$. To apply Vickers impressions on the samples, the hardness machine UV1 model manufactured by Koopa Company was utilized. To measure and observe the impressions made by the Vickers indenter on the samples, the hardness machine FM-700 model manufactured by Future Tech Company was employed. To study the microstructure 

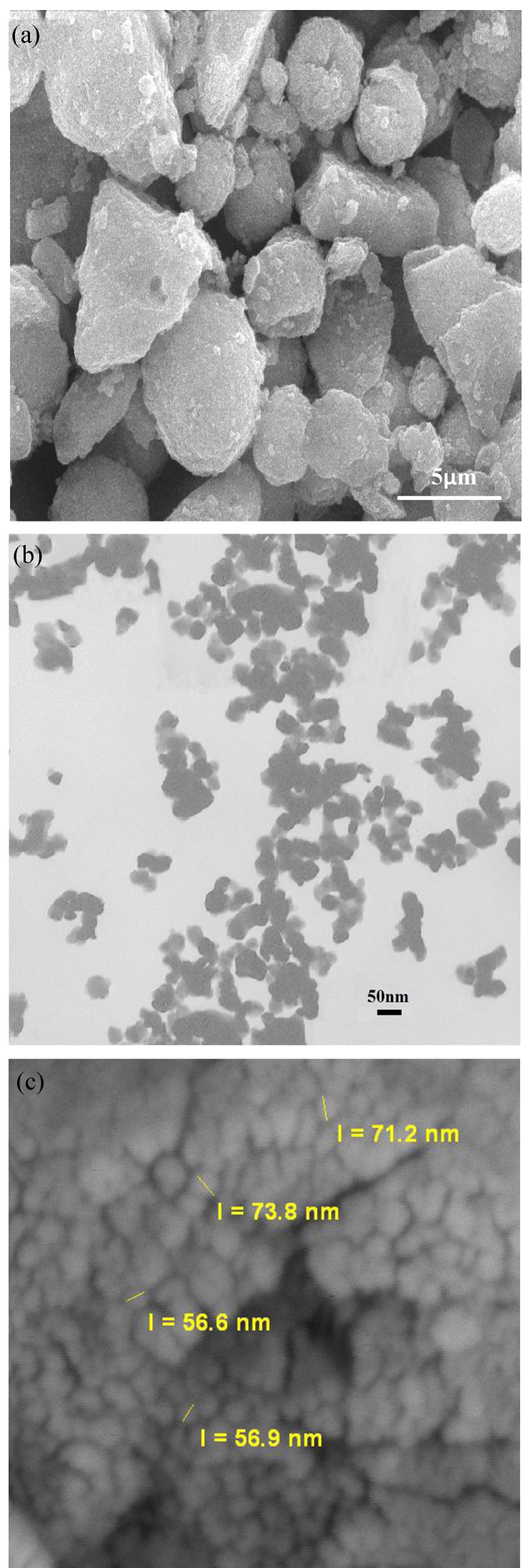

Fig. 2. Microstructural images: (a) SEM image of the alumina powder, (b) TEM image of the nanoSiC powder, and (c) SEM image of the nanoMgO powder. ${ }^{18)}$
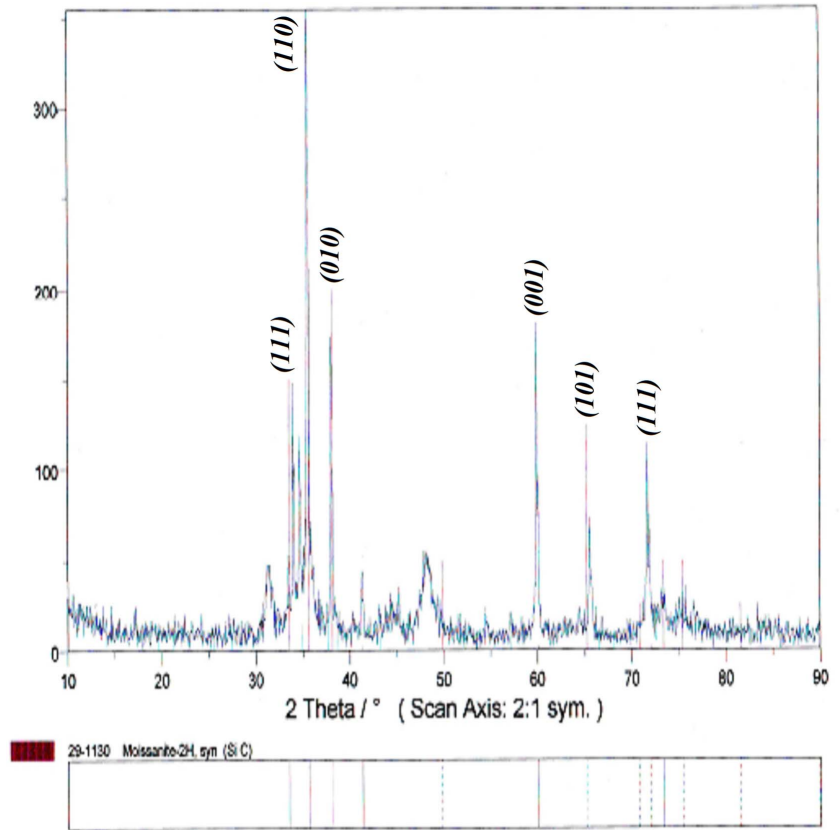

(a)

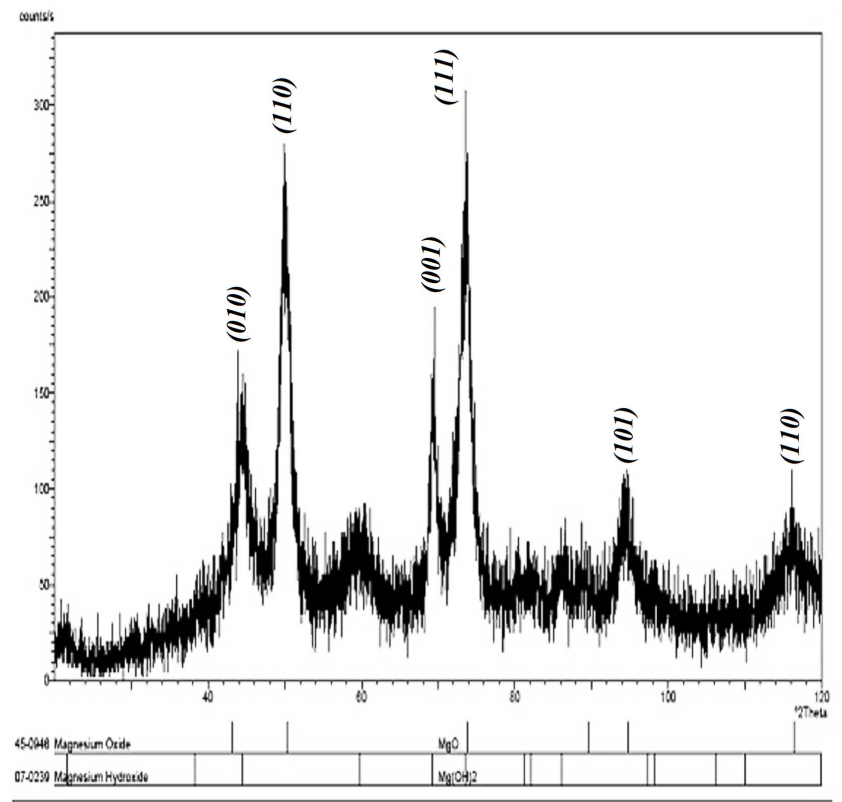

(b)

Fig. 3. (a) XRD pattern of nanoSiC; (b) XRD pattern of nanoMgO. ${ }^{18)}$

of the samples and perform calculations based on the Vickers impressions, a SEM manufactured by Philips Company (model XL30) was used at the voltage of $20 \mathrm{KV}$ and wavelength of $\lambda=1.54 \AA$. For phase analysis of the materials, the XRD equipment model 3003TT manufactured by Seifert Company was used.

\subsection{Procedure}

The samples were fabricated by using hot press method with simultaneous application of heat and pressure on the mixture of primary nanopowders. The value of the nano- 
$\mathrm{MgO}$ was $800 \mathrm{ppm}$ in proportion to the weight of the solid sample, whereas the values of the nanoSiC were $0,2.5,5$, $7.5,10$, and 15 vol.\%. After weighing the primary nanopowders, a suspension of their mixture was prepared in isopropanol and placed inside the ball-mill enclosure for homogenization for $3 \mathrm{~h}$. The ball-to-powder ratio was 14:1. Afterwards, the resulting mixture was placed in an oven at the temperature of $90^{\circ} \mathrm{C}$ for $24 \mathrm{~h}$. A mass of $330 \mathrm{~g}$ of the resulting powder then formed by using a press machine at a pressure of $2 \mathrm{MPa}$ for $30 \mathrm{~s}$. The resulting samples were placed in a hot-press machine for synthesis at the heating rate of $10^{\circ} \mathrm{C} / \mathrm{min}$ in argon atmosphere with a graphite mold at temperatures of $1600,1650,1700$, and $1750^{\circ} \mathrm{C}$ by simultaneously applying a pressure of $35 \mathrm{MPa}$ for three hours. Then, the furnace was turned off to allow the samples to lose their heat and cool naturally to the room temperature. By heating the samples at $1000^{\circ} \mathrm{C}$ inside a heat-treatment furnace for three hours, the graphite attached to the samples in the sintering phase was removed. Meanwhile, thermal etching of the samples was performed for the purpose of examination of their microstructures.

Five pieces of samples were prepared and their densities and porosities measured through Archimedes method based on ASTM B311 standard. ${ }^{19)}$ The theoretical density of the composite sample can be obtained from Eq. (1), in which the alumina density $\left(\mathrm{d}_{\mathrm{A}}\right)$ is equal to $3.986 \mathrm{~g} / \mathrm{cm}^{3}$, SiC density $\left(\mathrm{d}_{\mathrm{SiC}}\right)$ is equal to $3.217 \mathrm{~g} / \mathrm{cm}^{3},{ }^{20)}$ and $\mathrm{MgO}$ density is $3.58 \mathrm{~g} /$ $\mathrm{cm}^{3}{ }^{21)}$

$$
\mathrm{d}_{\text {com. }}=\mathrm{W}_{\mathrm{A}} \cdot \mathrm{d}_{\mathrm{A}}+\mathrm{W}_{\mathrm{SiC}} \cdot \mathrm{D}_{\mathrm{MgO}}+\mathrm{W}_{\mathrm{SiC}} \cdot \mathrm{D}_{\mathrm{MgO}}
$$

where $W_{A}$ is the weight fraction of the alumina powder, $W_{S i C}$ is the weight fraction of the nanoSiC, and $\mathrm{W}_{\mathrm{Mgo}}$ is the weight fraction of the nanoMgO in the composite.

The exterior volume $(\mathrm{V})$ of the experimental samples can be obtained by Eq. (2) as the difference between the immersion weight and the saturation weight.

$$
\mathrm{V}=\mathrm{M}-\mathrm{S}
$$

Assume that water weighs $1 \mathrm{~g}$. This assumption for water at room temperature would correspond to a volume of $1 \mathrm{~cm}^{3}$ with the approximation of one-thousandths, which can be calculated as the percentage of the open porosity volume with respect to its total volume. The apparent porosity is calculated by Eq. (3).

$$
\mathrm{P}=[(\mathrm{M}-\mathrm{D}) / \mathrm{V}] \times 100
$$

Water absorption (A) can be quantified as the percentage of the weight of absorbed water relative to the dry sample weight (Eq. (4)):

$$
\mathrm{A}=[(\mathrm{W}-\mathrm{D}) / \mathrm{D}] \times 100
$$

The apparent density (T) refers to a portion of the sample that is water proof and is obtained by Eq. (5).

$$
\mathrm{T}=\mathrm{D} /(\mathrm{D}-\mathrm{S})
$$

The relative fraction of the apparent density of the sample to its theoretical density is calculated according to Eq. (6).

$$
\% \text { R.D. }=\mathrm{T} / \mathrm{d}_{\mathrm{com} .} \times 100
$$

where $T$ is the nominal (apparent) density and $d_{\text {com. }}$ is the theoretical density of the composite. The flexural strength or modulus of rupture (MOR) of the samples was obtained based on ASTM C1161 standard ${ }^{22)}$ by using the three-point method and Eq. (7) with three repetitions of the measurement per sample.

$$
M O R=\frac{3 F l}{2 b d^{2}}
$$

where $F$ is the break force, $l$ is the support span, $b$ is the width of the sample, and $d$ is the thickness of the sample. The elasticity moduli of the samples can be obtained based on ASTM C769 standard $^{23)}$ by considering the changes in sonic velocity in the sample material. In this method, an ultrasonic pulse with the frequency of $4 \mathrm{MHz}$ that is generated by the energy converter machine Echometer1070 manufactured by Karl Deutsch Wuppertal and equipped with DSE Lemo probe, which converts electrical energy to sonic waves, is transmitted through each sample four times and the reflected wave measured. By recording the reversal time and measuring the sample thickness, the sonic velocity in the sample is determined. By using Eq. (8), the elasticity modulus (E) is obtained. ${ }^{23)}$

$$
E=\rho v^{2}
$$

where $\rho$ is the density of the sample and $v$ is the sonic velocity of the sample. The hardness values of the samples were calculated by Vickers method based on ASTM C1327 standard.$^{24)}$ By applying $49 \mathrm{~N}$ (5 kgf) load through a hardness machine for $30 \mathrm{~s}$, seven impressions of the Vickers indenter were created on each sample and, by using Eq. (9), the Vickers hardness $(\mathrm{H})$ was calculated.

$$
H=(1.8544) \frac{P}{d^{2}}
$$

where $P$ is the load applied for producing the Vickers impressions and $d$ is the average diameter of the Vickers impressions. The average resulting from the seven measurements of the hardness was reported as the sample hardness. By using Eqs. (10) to (12), the fracture toughness $\left(K_{I C}\right)$ values of the samples can be calculated. ${ }^{25-27)}$

$$
\begin{aligned}
K_{I C} & =0.00366\left(\frac{E}{H v}\right)^{1 / 2} t_{\text {Ave }}^{3 / 2} \frac{P}{A^{3 / 2}} \\
K_{I C} & =0.0889\left(\frac{H v \cdot P}{\sum_{i=1}^{4} C_{i}}\right)^{1 / 2} \\
K_{I C} & =0.0089\left(\frac{E}{H v}\right)^{2 / 5}\left(\frac{P}{a . C^{1 / 2}}\right)
\end{aligned}
$$

where $E$ is Young's modulus, $H v$ is Vickers hardness, $P$ is 
the load applied for creating the Vickers impressions, $t_{\text {ave }}$ is the average thickness of the microcracks formed around the indented section, $A$ is the surface area corresponding to the effect of the whole microcracks formed around the indented section of the sample, $C$ is the crack length of the median/ radial, and a is one-half of the diameter of the indented section on the sample that is created by the application of the Vickers diamond. The average resulting from the seven measurements was reported as the fracture toughness of the sample.

The surface morphologies of the samples and the dimensions and shapes of the nanoparticles were investigated by SEM in the secondary electron (SE) and back scattered electron (BSE) modes. Furthermore, the grain size of the matrix phase was calculated by using a Philips- FEGC200 transmission electron microscope.

\section{Results}

\subsection{Relative density}

Figure 4 shows the relative densities of the samples as functions of the sintering temperature for different volume fractions of nanoSiC. As observed, with the increase in the sintering temperature for all volume fractions of nanoSiC, the relative density increased. The increase in temperature causes the mobility of the grain boundaries and, as a result, alumina condensation is promoted. Wang et al. ${ }^{10)}$ showed that with the increase in the sintering temperature of an alumina nanocomposite containing $10 \mathrm{vol} \%$ nanoSiC up to $1700^{\circ} \mathrm{C}$, a density close to the theoretical density can be possibly realized. The results of this research also verify this finding. The increase in the temperature for different nanoSiC volume fractions eventually leads to an increase in the density up to the theoretical density. On the other hand,

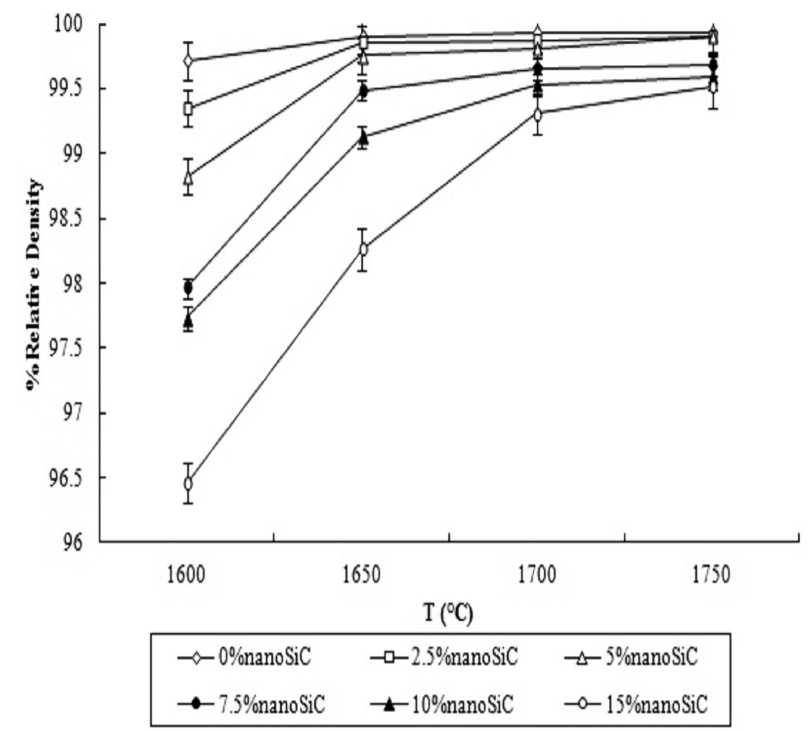

Fig. 4. Relative densities of the samples versus the sintering temperature for different nanoSiC volume fractions. addition of $\mathrm{SiC}$ nanoparticles decreases the density. It seems that at lower temperatures, this reduction in density has a greater effect due to the lower sintering capacities of the samples. The effect of increased temperature on the increase in the density would be different for different nanoSiC volume fractions, such that it is enormously increased upon increasing the nanoSiC volume fraction in the range of sintering temperatures 1600 to $1700^{\circ} \mathrm{C}$. Moreover, at all temperatures, the relative density decreases. Since nanoSiC particles contribute to the immobility of the grain boundaries and prevent $\mathrm{Al}_{2} \mathrm{O}_{3}$ condensation, the addition of nanoSiC leads to the relative density being decreased.

In addition, it is revealed that the relative density of the alumina sample containing no nanoSiC additive increases up to $99.9 \%$. The achievement of such a high density can be ascribed to the existence of $\mathrm{MgO}$. It is assumed that $\mathrm{MgO}$ forms a solid solution that reduces the volume of grain boundaries. Similarly, excessive grain growth is minimized. On the other hand, the increase in the surface permeability and mobility of the pores causes the porosity of the sample to be reduced. Therefore, the sample density is increased during sintering. ${ }^{16,17,28-30)}$

\subsection{Phase analysis, microstructure, and variations in the grain sizes of samples}

Figure 5 shows the XRD pattern of $\mathrm{Al}_{2} \mathrm{O}_{3}$-nanoSiC sample sintered at $1750^{\circ} \mathrm{C}$ with 15 vol.\% nanoSiC, in which the existence of $\alpha-\mathrm{Al}_{2} \mathrm{O}_{3}$ and $\alpha-\mathrm{SiC}$ without any reaction occurring between them at the experimental temperature and pressure has been illustrated.

Figure 6 presents the microstructures of some of the sintered samples obtained by SEM at different temperatures. As observed, with the increase in the sintering temperature, the alumina grains become larger; on the other hand, an increase in the volume fraction of nanoSiC prevents extreme growth of the alumina grains. Wang et al. ${ }^{17)}$ proved that monophase $\mathrm{Al}_{2} \mathrm{O}_{3}$ grains are large and heterogeneous and

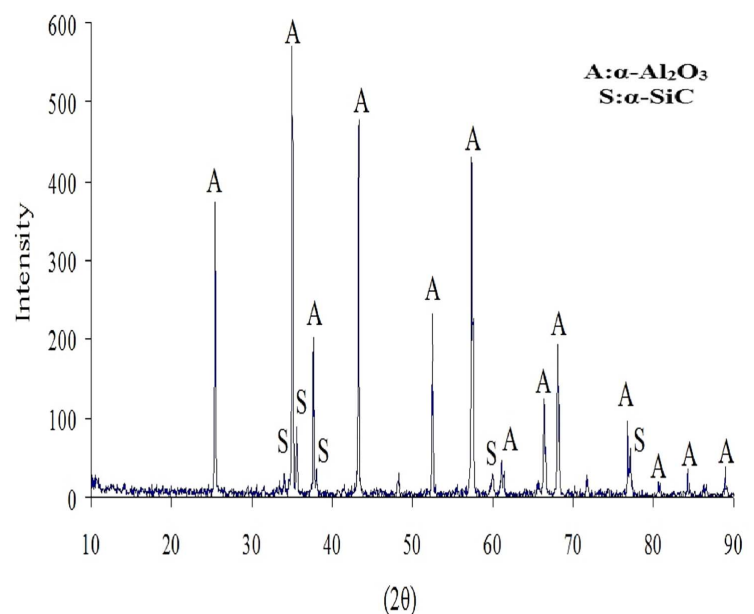

Fig. 5. XRD pattern of $\mathrm{Al}_{2} \mathrm{O}_{3}$-nanoSiC sample sintered at $1750^{\circ} \mathrm{C}$ with 15 vol. $\%$ nanoSiC (A: $\alpha-\mathrm{Al}_{2} \mathrm{O}_{3}$ and $\mathrm{S}: \alpha-$ $\mathrm{SiC})$ 

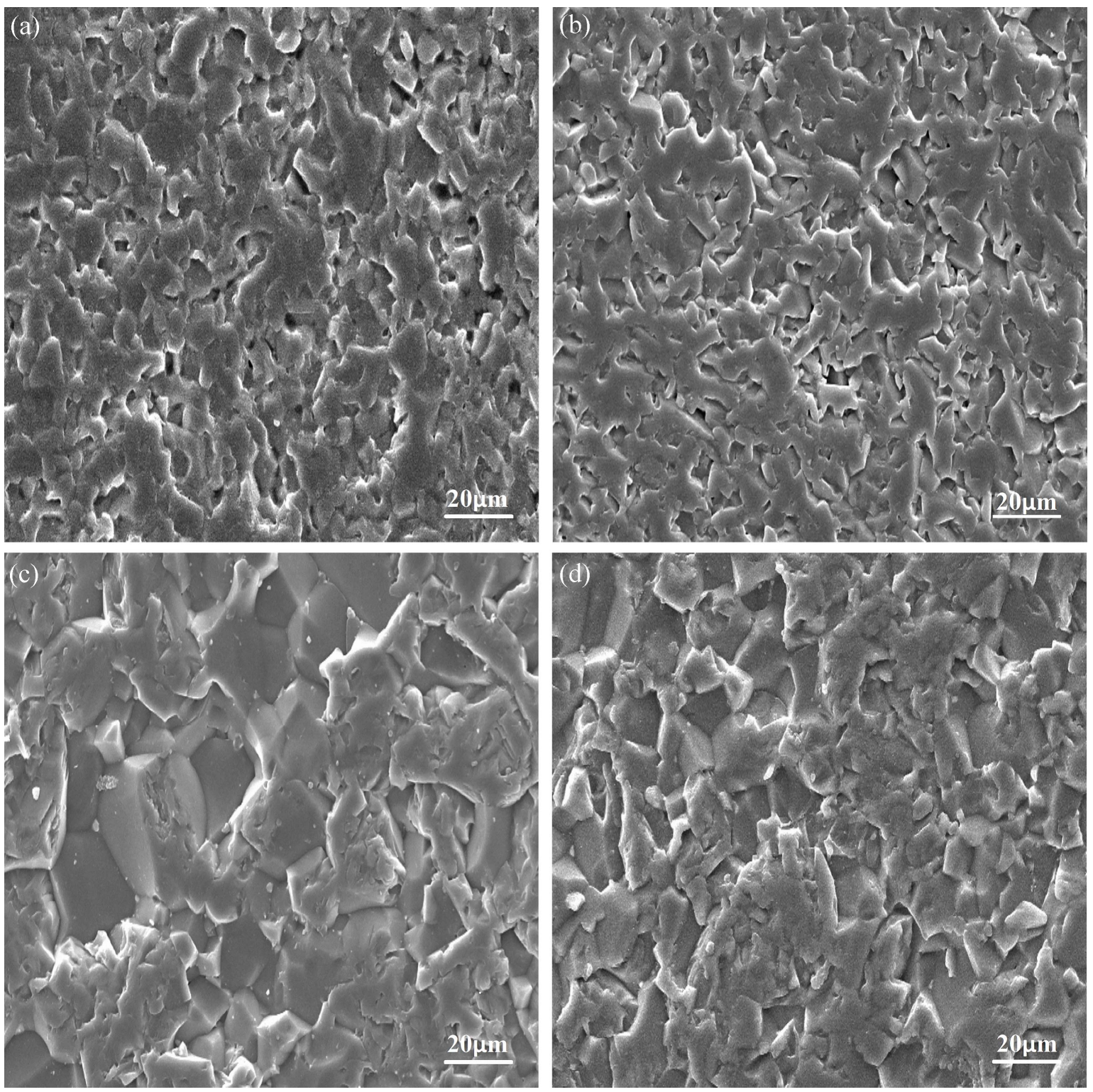

Fig. 6. Microstructures of the sintered samples corresponding to the conditions of (a) $1600^{\circ} \mathrm{C}$ and 0 vol. $\%$ nanoSiC; (b) $1600^{\circ} \mathrm{C}$ and 7.5 vol.\% nanoSiC; (c) $1750^{\circ} \mathrm{C}$ and 0 vol.\% nanoSiC; and (d) $1750^{\circ} \mathrm{C}$ and 7.5 vol.\% nanoSiC.

that some of the grains grow extraordinarily. However, the addition of nanoSiC particles inhibits the extraordinary growth of the grains and maintains a small grain size. In addition, the grains get homogenized in the composite.

Based on Fig. 6, with the increase in the nanoSiC volume fraction in the samples, the grain size decreases at all the temperatures, which can be attributed to the lack of reaction between the nanoSiC particles and the alumina matrix at the sintering temperatures and to the effect of the nanoSiC particles in reducing the mobility of the grain boundaries. ${ }^{10,31-34)}$ Furthermore, it has been demonstrated that based on Zener model, the secondary phase refrains from the growth of matrix grains, the size of which $(\mathrm{G})$ can be obtained from Eq. (13). ${ }^{17)}$

$$
\mathrm{G}=4 \mathrm{r} / 3 \mathrm{f}
$$

where $r$ is the radius of the grains of the secondary phase and $f$ is the volume fraction of the secondary phase. This equation shows that with the increase in the volume fraction of the secondary phase, the grain size of the matrix is decreased. Fig. 7 shows a TEM image of the microstructure of a nonadditive sample that was sintered at $1600^{\circ} \mathrm{C}$. Based on the figure, the average size of the sample seed is about 6 $\mu \mathrm{m}$.

In Fig. 8, the average grain sizes of the samples have been shown as functions of the sintering temperature for different nanoSiC volume fractions. This figure reveals that with the increase in temperature, the grain size increases for all the cases. With the addition of nanoSiC particles, the rate of 


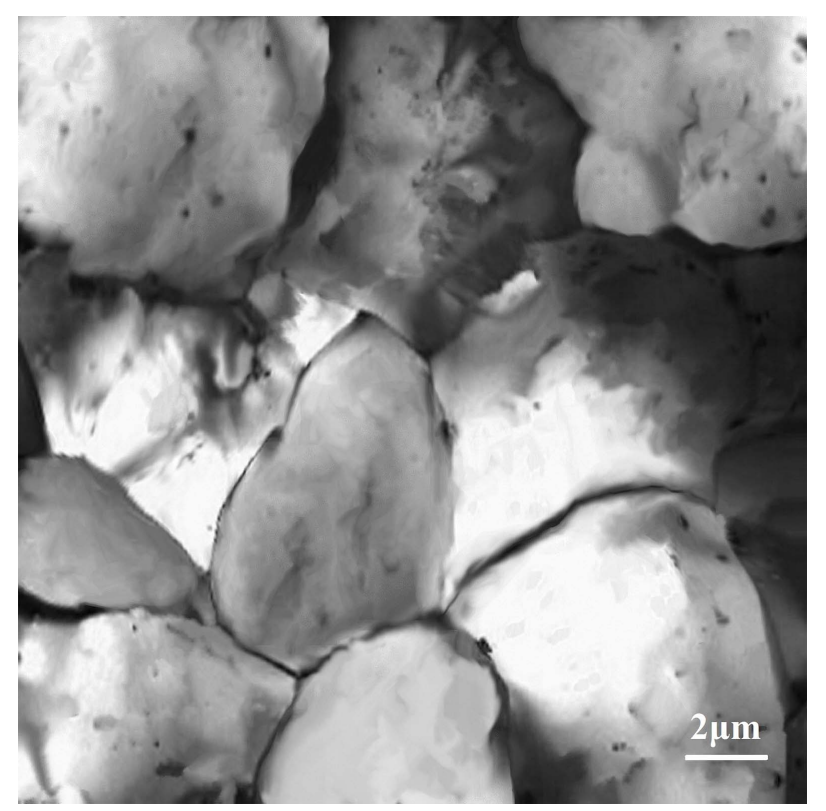

Fig. 7. TEM image of the microstructure of the sample sintered at $1600^{\circ} \mathrm{C}$ with 0 vol. $\%$ nanoSiC.

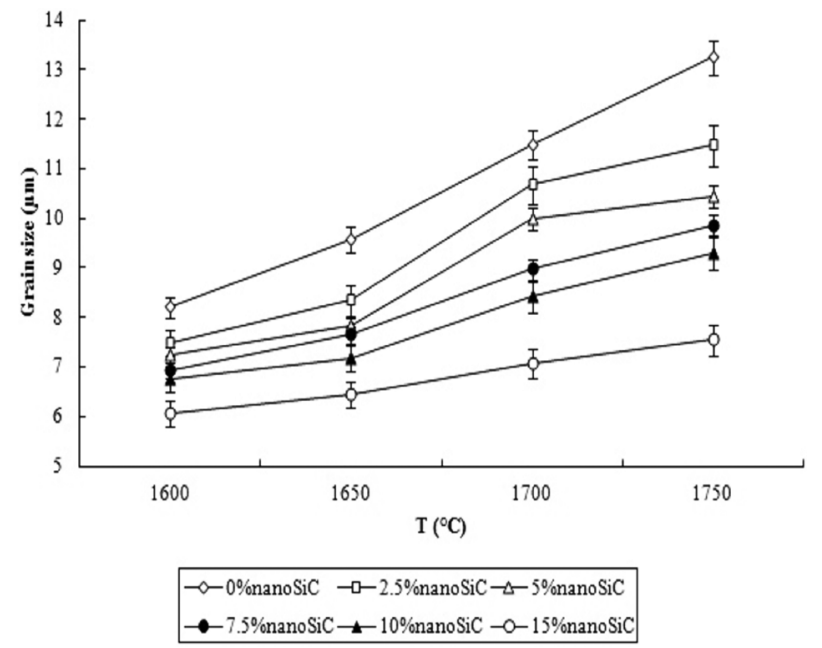

Fig. 8. Average grain sizes of the samples as functions of sintering temperature for different nanoSiC volume fractions.

increase in the grain size is reduced, so that the maximum increase in the grain size is for the nonadditive sample, about $61 \%$, and the minimum value is for the sample containing 15 vol.\% nanoSiC, roughly $24 \%$. Moreover, the alumina grain size of the samples increases from the maximum initial size of $5 \mu \mathrm{m}$ to about $6-14 \mu \mathrm{m}$.

Figures 9(a) and 9(b) show the microstructural SEM images of the sample containing 2.5 vol.\% nanoSiC and sintered at $1600^{\circ} \mathrm{C}$ and the sample containing 7.5 vol.\% nanoSiC and sintered at $1700^{\circ} \mathrm{C}$, respectively, which were obtained by using a BSE detector. As is evident, the nanoSiC particles are located at the grain boundaries and inside the alumina grains. With the increase in the nanoSiC volume fraction, its effect in preventing grain growth does not
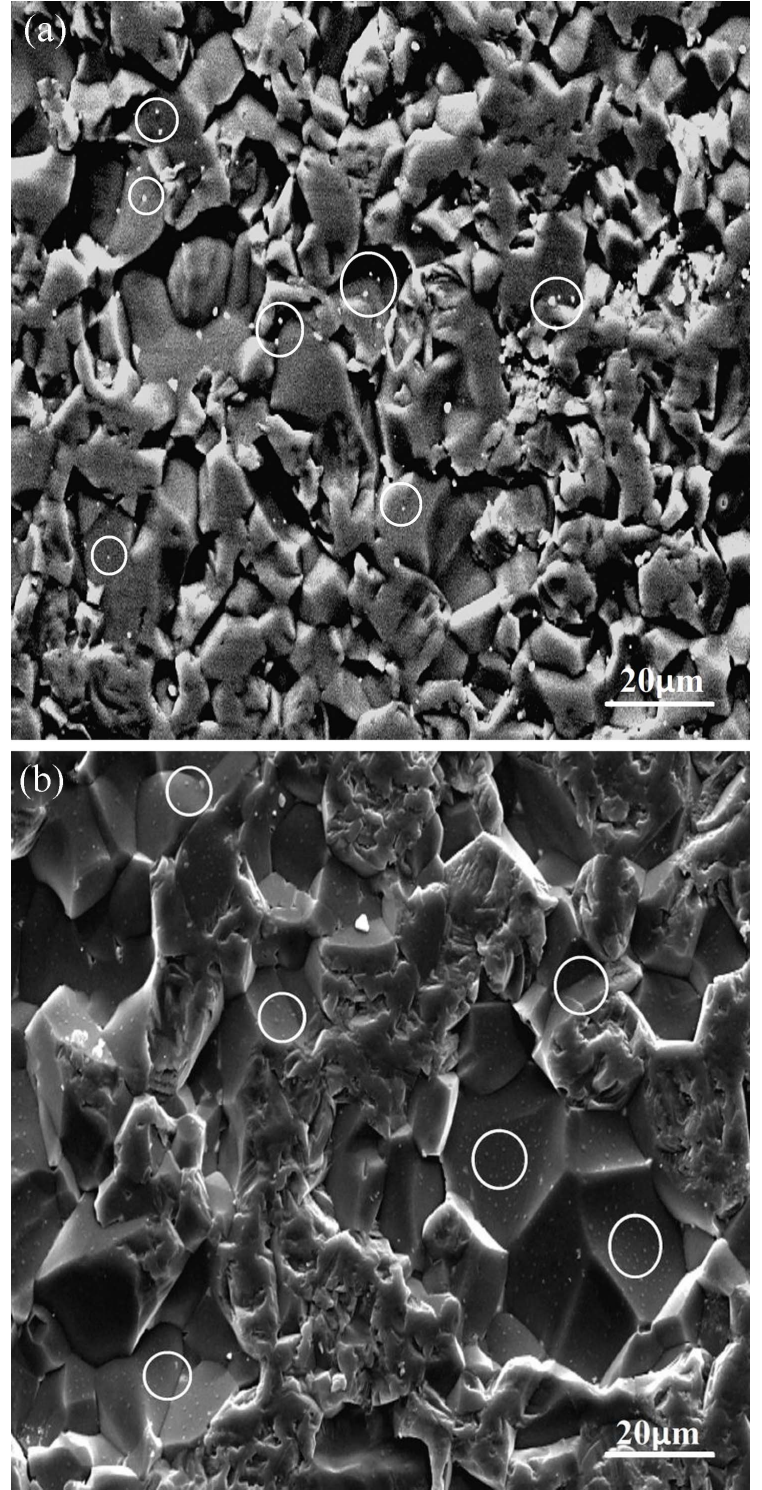

Fig. 9. SEM images of the microstructures of the samples sintered at (a) $1600^{\circ} \mathrm{C}$ with 2.5 vol. $\%$ nanoSiC, and (b) $1700^{\circ} \mathrm{C}$ with 7.5 vol. $\%$ nanoSiC. (The spots indicated by white circles show a portion of the SiC particles).

increase linearly. The reason is that, for example, when the $\mathrm{SiC}$ volume fraction is duplicated, a substantial fraction of the particles will occupy the interior of the alumina grains, which implies that the nanoSiC particles existing at the grain boundaries and preventing their growth have not been duplicated. Moreover, owing to the increase in the sintering temperature, the effect of the added nanoSiC particles in inhibiting grain growth will be somewhat decreased. ${ }^{10)}$

Alumina grain overgrowth often occurs owing to the extremely high energy. Controlling the grain growth in terms of its size and morphology is highly important, as it plays an important role in determining the quality of the produced material; in addition, realizing a high density that is required to stop the growth during sintering is crucial. 
Therefore, the inhibition of grain growth is utilized as part of the solid solution mechanism in the production of alumina. The important effects of adding $\mathrm{MgO}$ include a reduction in the mobility of the grain boundaries, an increase in the surface permeation, and, as a result, an increase in the mobility of the pores, an increase in the condensation with increases in the grain boundaries and network permeation, and reductions in the surface energy and nonuniformity of the grains. Moreover, as the $\mathrm{SiC}$ particles do not have enough mobility and do not react with $\mathrm{Al}_{2} \mathrm{O}_{3}$ at the sintering temperature, they reduce the mobility of the grain boundaries and, as a result, prevent the $\mathrm{Al}_{2} \mathrm{O}_{3}$ condensation. Therefore, after the addition of $\mathrm{SiC}$ nanopowder, this issue is addressed by increasing the sintering temperature.

\section{Discussion}

\subsection{Elasticity modulus}

The elasticity moduli of the samples have been shown as functions of the sintering temperature for different volume fractions of nanoSiC in Fig. 10. As seen, with the increase in temperature, the elasticity modulus increases for all the samples, which can be due to the completely sintered particles. With complete sintering, the porosity of samples is reduced and the sonic velocity is increased throughout the sample, which causes the elasticity modulus to be enhanced. ${ }^{31)}$ The elasticity moduli of the sintered samples follow increasing trends up to 7.5 vol.\% of nanoSiC at 1700 and $1750^{\circ} \mathrm{C}$, before decreasing. The increased elasticity modulus upon adding nanoSiC can be ascribed to the relatively high elasticity modulus of $\mathrm{SiC}$ compared to that of $\mathrm{Al}_{2} \mathrm{O}_{3} \cdot{ }^{31)}$ The elasticity modulus of monocomponent alumina has been reported to be roughly $340-400 \mathrm{GPa}$ in the literature ${ }^{2,32)}$ which suggests that the elasticity moduli of the nonadditive samples, which are in the range 401-426 GPa, exceed that of mono-

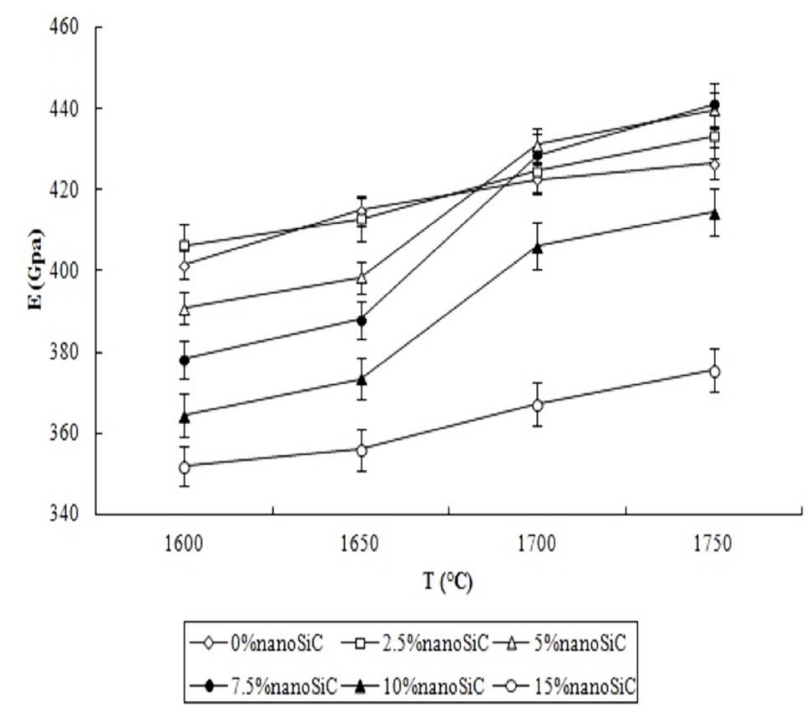

Fig. 10. Elasticity moduli of the samples as functions of sintering temperature for different volume fractions of nanoSiC. component alumina. Anya et $a l^{31)}$ achieved the maximum elasticity modulus of $409.5 \mathrm{GPa}$ for a sample with a relative density of $99.6 \%$ that was obtained through pressure-off synthesis and sintering of $\mathrm{Al}_{2} \mathrm{O}_{3}-\mathrm{SiC}$ nanocomposites. Moreover, Moradkhani et al..$^{33)}$ obtained an elasticity modulus of $402 \mathrm{GPa}$ for hot press sintered alumina samples containing 15 vol.\% $800 \mathrm{~nm} \mathrm{SiC} \mathrm{particles} \mathrm{at} 1700^{\circ} \mathrm{C}$. The results indicate an increase in the elasticity modulus of the composite.

According to the combination law for a particle (powder) composite with a random phase distribution, the elasticity modulus of the composite can be calculated by using Eq. (14), based on the elasticity modulus of the components.

$$
E=\Sigma E i . V i
$$
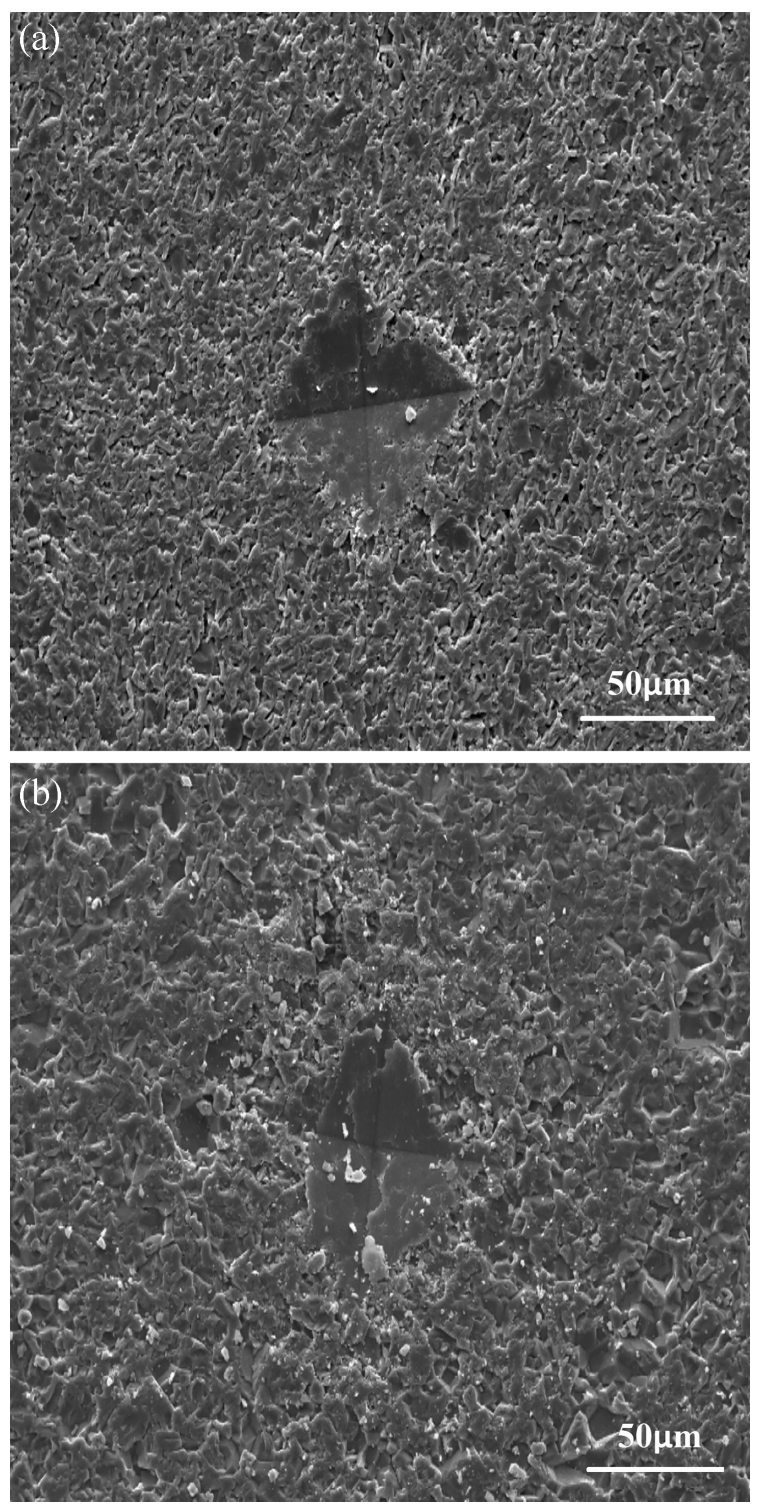

Fig. 11. Microstructural SEM images of the Vickers impressions created on the samples. (a) with 2.5 vol. $\%$ nanoSiC and sintered at $1600^{\circ} \mathrm{C}$; (b) with 5 vol.\% nanoSiC and sintered at $1700^{\circ} \mathrm{C}$ for the determination of hardness. 
Where $E_{i}$ and $V_{i}$ are the elasticity modulus and volume ratios, respectively, of the components of a composite. Therefore, Eq. (15) is obtained for $\mathrm{Al}_{2} \mathrm{O}_{3}-\mathrm{SiC}$ composite.

$$
E_{\text {comp }}=E_{A} \cdot V_{A}+E_{S} \cdot V_{S}
$$

where Ecomp is the elasticity modulus of the composite, $E_{A}$ is the elasticity modulus of $\mathrm{Al}_{2} \mathrm{O}_{3}$, equal to $380 \mathrm{GPa}$, and $E_{S}$ is the elasticity modulus of $\mathrm{SiC}$, equal to $414 \mathrm{GPa}^{34)}$ Therefore, it is expected that with the increase in the amount of $\mathrm{SiC}$, the elasticity modulus of the composite will increase. In contrast, the increase in $\mathrm{SiC}$ volume fraction leads to a decreased density and the creation of pores that contributes to a reduction in the sonic velocity in the sample and, hence, the elasticity modulus is decreased. ${ }^{31)}$

\subsection{Hardness}

Figure 11 illustrates the Vickers impressions produced on a few samples for the determination of their hardness. In Fig. 12, the hardness values of the samples have been presented in terms of the sintering temperature for different volume fractions of nanoSiC. It is revealed that with the increase in the sintering temperature up to $1650^{\circ} \mathrm{C}$, the hardness is increased for all the samples, which can be caused by the completely sintered particles, whereas after that, the hardness decreases owing to grain growth. ${ }^{35,36)}$ The hardness of the alumina sample without nanoSiC added is $12 \mathrm{GPa}$ (which is the least) at $1600^{\circ} \mathrm{C}$, which is increased to nearly $17 \mathrm{GPa}$ at $1700^{\circ} \mathrm{C}$. The hardness of monocomponent alumina was reported to be about $12-18 \mathrm{GPa} .{ }^{3)}$ In addition, the hardness of the sintered samples increases upon increasing the nanoSiC volume fraction up to 7.5 vol.\% at all the temperatures, which can be attributed to the finer grains existing in the structure with the increase in the nanoSiC volume fraction. ${ }^{31)}$ The hardness of $\mathrm{Al}_{2} \mathrm{O}_{3}-\mathrm{SiC}$ nanocomposite containing 20 vol.\% $200 \mathrm{~nm}$ SiC particles prepared by hot press method at $1740^{\circ} \mathrm{C}$ reaches $19.7 \mathrm{GPa}$

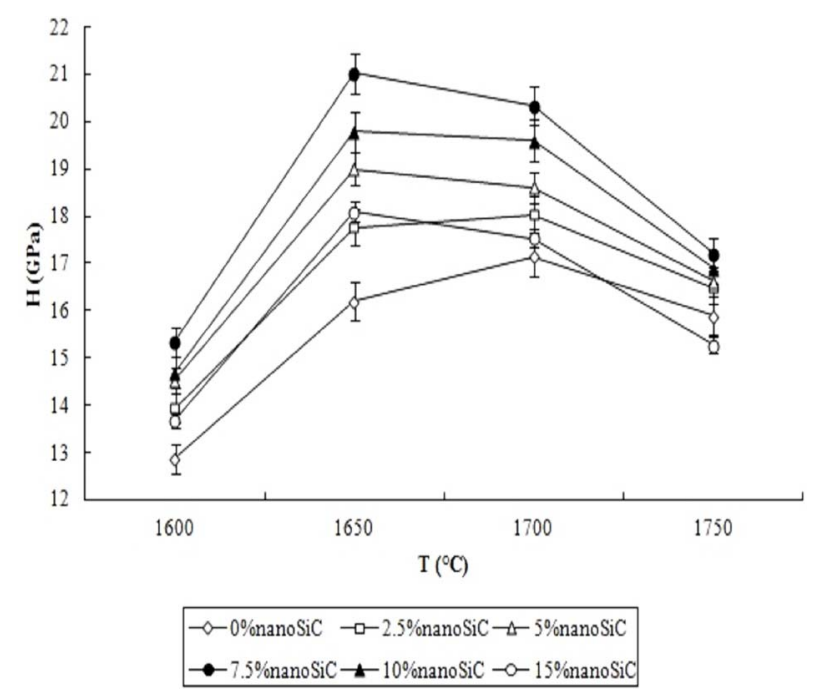

Fig. 12. Hardness of the samples as functions of sintering temperature for different nanoSiC volume fractions. maximum, which is approved based on the current findings. ${ }^{12)}$ It seems that with the increase in the nanoSiC volume fraction beyond $10 \mathrm{vol} . \%$, the porosity is increased, while the density is decreased, which cause a reduction in the hardness. On the other hand, agglomeration of the nanoSiC particles increases and their distribution homogeneity in the alumina matrix decreases, and hence, the hardness declines. In addition, with the increase in the nanoSiC volume fraction of the composite, the residual stress resulting from the discrepancy in thermal expansion between SiC? and $\mathrm{Al}_{2} \mathrm{O}_{3}$ increases, until it is released, which leads to the formation of microcracks in nanoSiC; as a result, the hardness is reduced. ${ }^{36)}$

\subsection{Fracture toughness}

Figure 13 displays the changes in the fracture toughness of the samples resulting from Eqs. (10) to (12) as functions of the sintering temperature. Through careful attention and comparison of the results, it can be learned that the findings from Eq. (10), which have been recently presented and used for a few brittle materials, ${ }^{33,37-40)}$ exhibit a high accuracy. As it turned out from the comparison of the results, the difference between the findings from Eq. (10) and all the other findings is less than $13 \%$ for all the cases.

As observed, with the increase in the sintering temperature up to $1650^{\circ} \mathrm{C}$, the fracture toughness is increased, owing to the samples being completely sintered. Further increases in temperature lead to minor changes in the fracture toughness of the samples. The reduction in the fracture toughness with the increase in temperature can be ascribed to increased grain size; on the other hand, the increase in the fracture toughness caused by an increase in temperature can be attributed to a reduction in the defects and pores, which are sources of cracks. ${ }^{31,35)}$ The increase in the fracture toughness at $1750^{\circ} \mathrm{C}$ can be attributed to the formation of combined phases such as mullite $\left(3 \mathrm{Al}_{2} \mathrm{O}_{3} \cdot 2 \mathrm{SiO}_{2}\right)$, which results from the reaction of $\mathrm{SiO}_{2}$, available at the $\mathrm{SiC}$ particle surfaces, with alumina, and also to the partial formation of the spinel phase $\mathrm{MgO} \cdot \mathrm{Al}_{2} \mathrm{O}_{3}$ at high temperatures. The resulting phases can be observed at the grain boundaries and pores, and resist crack growth, thus increasing the fracture toughness. ${ }^{11)}$ Moreover, the fracture toughness of the samples is increased by adding nanoSiC up to 5 vol.\% and, in some cases, up to 7.5 vol.\%. The mechanisms of enhancement in fracture toughness that include crack deflection and microcrack toughening have been proposed for the improvement in the toughness upon increasing the nanoSiC volume fraction. ${ }^{30)}$ Other studies also verify the increase in the fracture toughness of alumina samples, from almost 1.2 to $4.5 \mathrm{MPa}^{\mathrm{m}}{ }^{1 / 2}{ }^{33)}$ The fracture toughness of alumina nanocomposites containing $\mathrm{SiC}$ additive has been reported to be in the range $2-4.5 \mathrm{MPa} \cdot \mathrm{m}^{1 / 2}$, which is in agreement with the current findings. ${ }^{2,12)}$

With the increase in the nanoSiC volume fraction, the agglomeration of the nanoSiC particles is increased and their distribution homogeneity in the alumina matrix is 

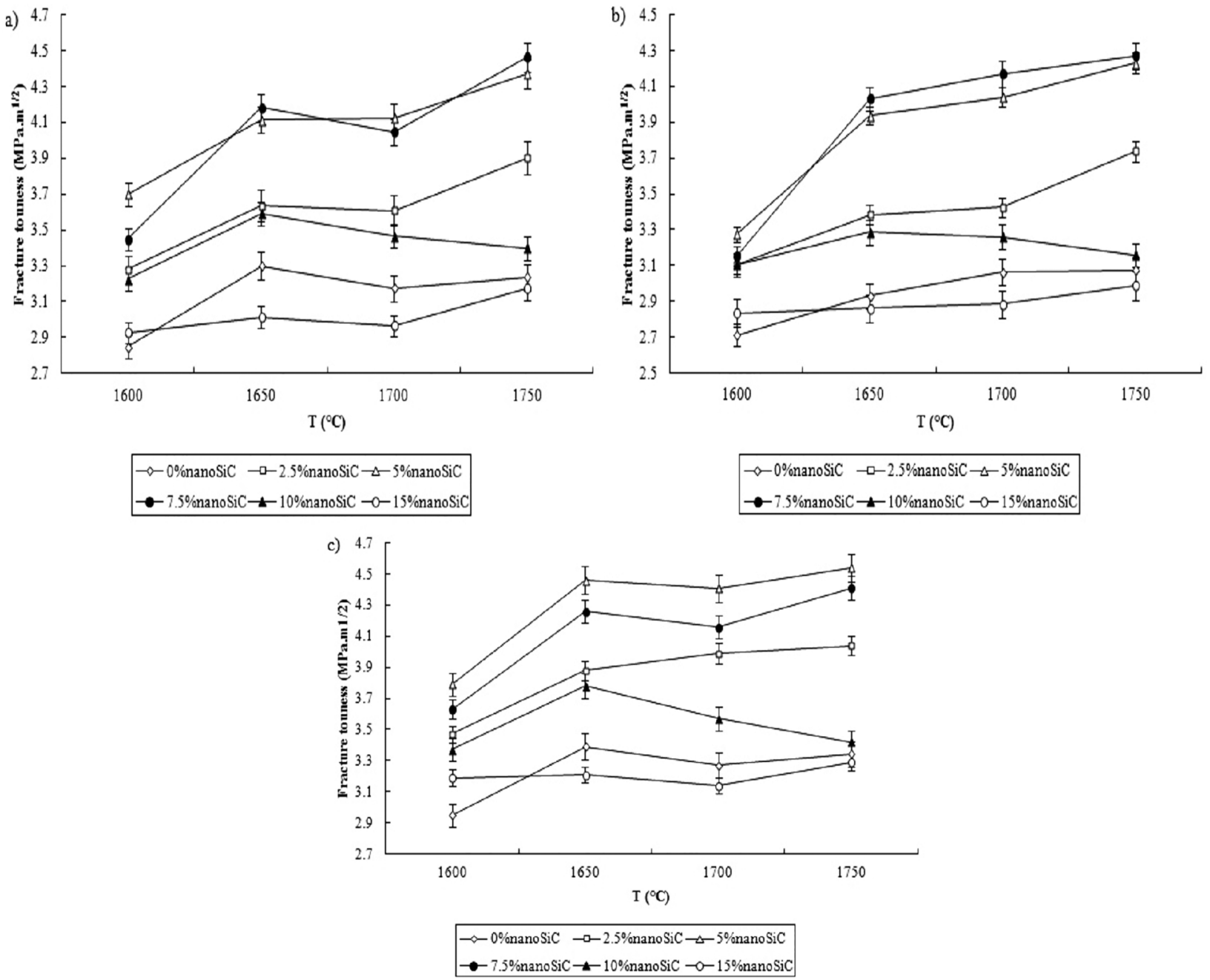

Fig. 13. Fracture toughness of the samples as functions of sintering temperature for different nanoSiC volume fractions, obtained by using Eqs. (a) (10), (b) (11), and (c) (12)

decreased. On the other hand, the residual stress resulting from the discrepancy in thermal expansion between $\mathrm{SiC}$ ? and $\mathrm{Al}_{2} \mathrm{O}_{3}$ is increased, which is eventually released, causing the grain boundaries to get clinched. As a result, with the decrease in the resistance to crack formation, the fracture toughness is also reduced. ${ }^{36,41)}$

\subsection{Flexural strength}

Figure 14 shows the flexural strengths of the samples as functions of the sintering temperature for different nanoSiC volume fractions. As is evident, the flexural strength continuously decreases with the increase in the sintering temperature for the nonadditive sample and the sample with 2.5 vol.\% nanoSiC. This can be attributed to the increase in the grain size during the rise in temperature, which decreases the flexural strengths of the samples. In the samples with 5 vol.\% or more nanoSiC, the temperature required for complete sintering of the samples is increased, owing to the existence of $\mathrm{SiC}$ particles and the high melting temperature of $\mathrm{SiC}$ (nearly $2670^{\circ} \mathrm{C}$ ), compared to that of $\mathrm{Al}_{2} \mathrm{O}_{3}$ (roughly $\left.2050^{\circ} \mathrm{C}\right) .{ }^{2)}$ Consequently, the increase in the temperature up to $1650^{\circ} \mathrm{C}$ contributes to the increase in the sintering capacity of the sample being more than the increase in the grain size. Thus, the flexural strength of the sample is increased.

However, the increase in the sintering temperature to $1700^{\circ} \mathrm{C}$ results in a notable increase in the grain growth. This increase in the grain growth has a more significant impact on the flexural strength in comparison to the increase in the sintering temperature from 1650 to $1700^{\circ} \mathrm{C}$, which causes the strengths to be decreased. ${ }^{35)}$

In the samples containing more than 2.5 vol.\% nanoSiC, the increase in the temperature up to $1750^{\circ} \mathrm{C}$ leads to an increase in the strength. This can be described by the formation of combined phases such as mullite $\left(3 \mathrm{Al}_{2} \mathrm{O}_{3} \cdot 2 \mathrm{SiO}_{2}\right)$, which results from the reaction of $\mathrm{SiO}_{2}$, available at the $\mathrm{SiC}$ particle surfaces, with alumina, and also to the partial formation of the spinel phase $\mathrm{MgO} \cdot \mathrm{Al}_{2} \mathrm{O}_{3}$ at high temperatures. The resulting phases can be observed at the pores and grain boundaries, and resist the crack growth caused by stress, thus increasing the strength. ${ }^{11,41,42)}$ The flexural 


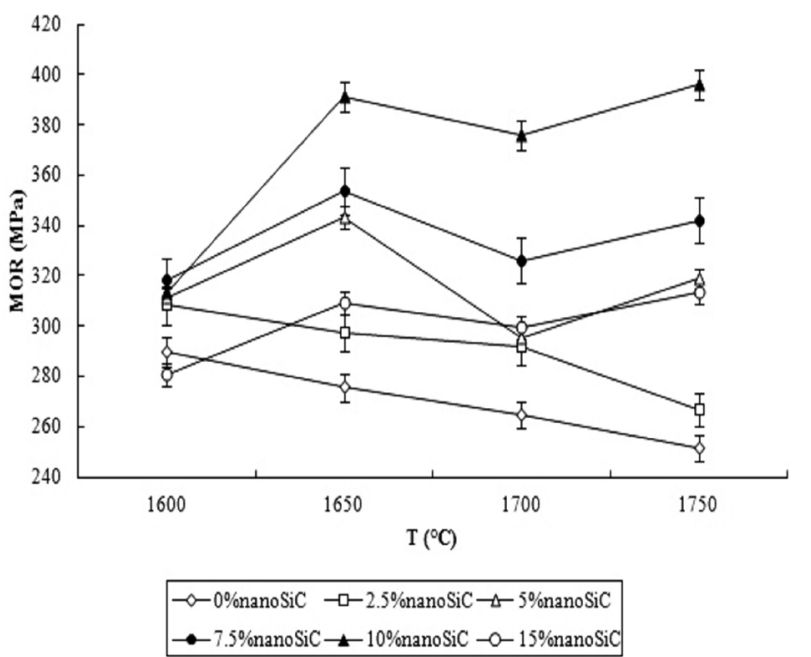

Fig. 14. Flexural strengths of the samples as functions of sintering temperature for different nanoSiC volume fractions.

strengths of the samples increase upon adding nanoSiC up to 10 vol.\%. A portion of this increase can be attributed to the finer grains existing in the structure upon the addition of the SiC nanoparticles. ${ }^{36)}$ That is because the nanoSiC particles lack sufficient mobility, and also because they do not react with alumina, which reduce the mobility of the grain boundaries. Therefore, a structure with smaller grain dimensions can be obtained.

It seems that with the increase in the amount of nanoSiC, in addition to increasing the porosity and decreasing the density, the agglomeration of the nanoSiC particles is increased and their distribution homogeneity in the alumina matrix is decreased. Thus, the flexural strength is decreased. On the other hand, with the increase in the nanoSiC volume fraction of the composite, the residual stress resulting from the discrepancy in thermal expansion coefficient between $\mathrm{SiC}$ and $\mathrm{Al}_{2} \mathrm{O}_{3}$ is increased, until it is released, which produces microcracks in nanoSiC; as a result, the strength is decreased. ${ }^{36)}$ The flexural strength of monocomponent alumina has been reported to be about 270-370 MPa in the literature, ${ }^{3)}$ the current findings reveal higher flexural strengths of monocomponent alumina in some cases. The highest strength is obtained for the sample containing $10 \mathrm{vol} . \%$ nanoSiC at the sintering temperature of $1650^{\circ} \mathrm{C}$ or higher; this reflects the increase in the flexural strength of alumina from $251 \mathrm{MPa}$ in the nonadditive nanoSiC sample to $396 \mathrm{MPa}$ in a sintered sample at $1750^{\circ} \mathrm{C}$, which correspond to an increase of $57 \%$.

Figure 15 shows the changes in the flexural strengths of the samples as functions of the grain size at different sintering temperatures. As observed, with the decrease in the grain size, the strength is increased. However, in the sample with 15 vol.\% nanoSiC, the strength decreases, which can be ascribed to the increase in porosity and release of the residual stress developed inside the grains. ${ }^{36)}$

Adding SiC particles leads to homogeneity of the struc-

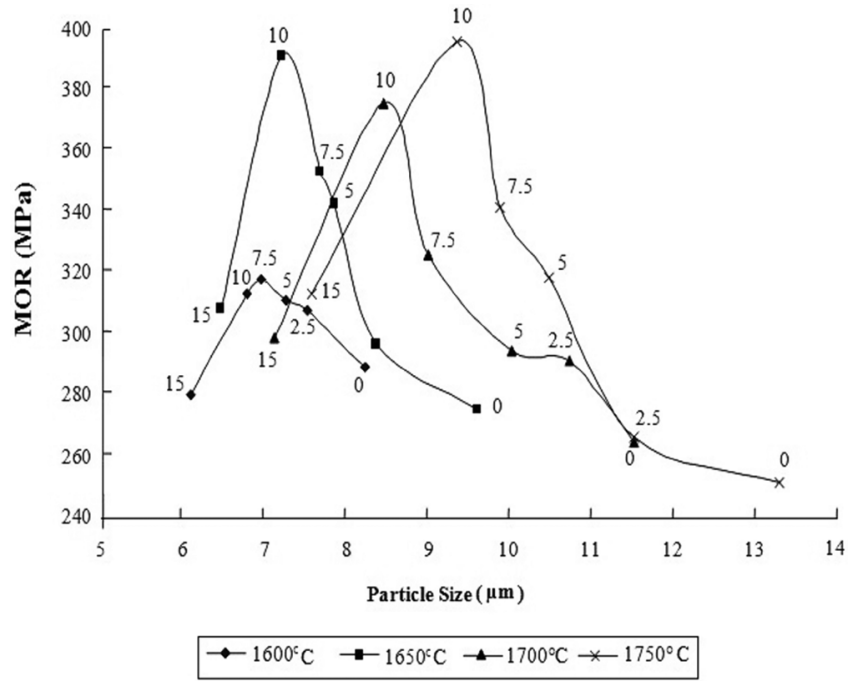

Fig. 15. Flexural strengths of the samples as functions of their grain size at different sintering temperatures (the numbers beside the signs indicate the volume fractions of nanoSiC).

ture, in addition to preventing extraordinary growth of the grains and maintaining their dimensions small, which heavily impacts their mechanical properties, including the increase in the flexural strength. On the other side, because the residual stress originating from the discrepancy in the thermal expansion coefficient between $\mathrm{SiC}$ and $\mathrm{Al}_{2} \mathrm{O}_{3}$, strengthens the grain boundaries, the flexural strength increases. ${ }^{42)}$ The relation between the yield stress $\left(\sigma_{y}\right)$ and the grain diameter (d), called Hall-Petch equation, has been expressed in Eq. (16). ${ }^{43)}$

$$
\sigma_{y}=\sigma_{0}+\frac{k}{\sqrt{d}}
$$

Here, $\sigma_{0}$ is a material constant denoting the initial stress in the dislocation direction and $k$ is an inherent constant of the material. The Hall-Petch equation verifies the increased strength of the material with the decrease in the grain size. The thermal expansion coefficient of alumina in the temperature range $0-1727^{\circ} \mathrm{C}$ is increased to be roughly $8.58 \times$ $10^{-6} /{ }^{\circ} \mathrm{C}$, whereas the thermal expansion coefficient of $\mathrm{SiC}$ is nearly $4.70 \times 10^{-6} /{ }^{\circ} \mathrm{C}$ in the temperature range $0-1700^{\circ} \mathrm{C} .{ }^{42)}$ As a consequence, when cooling a $\mathrm{Al}_{2} \mathrm{O}_{3} / \mathrm{SiC}$ composite sample in a hot press furnace after heat treatment, the $\mathrm{Al}_{2} \mathrm{O}_{3}$ particles tend to shrink more than the $\mathrm{SiC}$ particles, which produces a compressive stress on the nanoSiC particles present at the grain boundaries, which ultimately increases the resistance of the grain boundaries to slippage. Thus, the strength of a sample is increased upon adding nanoSiC particles. $^{44)}$

\section{Conclusions}

This study investigated the effect of sintering temperature on the mechanical characteristics of alumina-based 
nanocomposites containing nanoMgO and nanoSiC additives and analyzed their microstructures. The results obtained can be summarized as follow.

With the increase in the sintering temperature, the relative density is increased for all nanoSiC volume fractions, so that the relative density is increased from about $96.5 \%$ for 15 vol.\% nanoSiC sample sintered at $1600^{\circ} \mathrm{C}$ to $99.5 \%$ for the sample sintered at $1750^{\circ} \mathrm{C}$. Furthermore, the relative density of the alumina sample containing nanoMgO without any nanoSiC additive increases to $99.9 \%$, which decreases with the increase in nanoSiC volume fraction at all the sintering temperatures. The realization of such a high density can be ascribed to the existence of $\mathrm{MgO}$.

The XRD pattern of the $\mathrm{Al}_{2} \mathrm{O}_{3}-5$ vol.\% nanoSiC sample containing $\alpha-\mathrm{Al}_{2} \mathrm{O}_{3}$ and $\alpha-\mathrm{SiC}$ shows that no considerable reaction takes place between $\mathrm{Al}_{2} \mathrm{O}_{3}$ and nanoSiC at the experimental pressure and temperature.

The alumina grain size varies from $6.06 \mu \mathrm{m}$ for the sample containing 15 vol.\% nanoSiC sintered at $1600^{\circ} \mathrm{C}$ to 13.25 $\mu \mathrm{m}$ for the nonadditive sample sintered at $1750^{\circ} \mathrm{C}$. With the decrease in the sintering temperature and increase in the nanoSiC volume fraction, the alumina grain size increases.

The elasticity moduli of the samples are in the range 401$426 \mathrm{GPa}$, which follows an increasing trend up to 7.5 vol.\% nanoSiC, before decreasing, for the samples sintered at 1700 and $1750^{\circ} \mathrm{C}$ and containing nanoSiC additive. The increased elasticity modulus upon adding nanoSiC can be ascribed to the relatively high elasticity modulus of $\mathrm{SiC}$ compared to that of $\mathrm{Al}_{2} \mathrm{O}_{3}$. In contrast, the increase in $\mathrm{SiC}$ volume fraction leads to decreased density and formation of pores, which contributes to the reduction in the sonic velocity in the sample and, thus, the elasticity modulus is decreased.

The minimum hardness value of nearly $12 \mathrm{GPa}$ corresponds to the nonadditive alumina sample sintered at $1600^{\circ} \mathrm{C}$, and reaches the maximum of $21 \mathrm{GPa}$ upon increasing the sintering temperature to $1650^{\circ} \mathrm{C}$ and adding 7.5 vol.\% nanoSiC, which suggests an increase of $63 \%$. The hardness of the sintered samples is increased by increasing the nanoSiC vol.\% up to 7.5 vol.\% at all the temperatures, which can be attributed to the finer grains existing in the structure upon increasing the nanoSiC volume fraction.

Upon adding nanoSiC up to 7.5 vol.\%, the fracture toughness of the samples is increased; at higher values of nanoSiC addition, the fracture toughness decreases. The increase in the fracture toughness caused by the increase in temperature can be attributed to a reduction in the defects and pores, which are sources of cracks. On the other hand, the reduction in the fracture toughness observed with increasing temperature can be ascribed to the increased grain size. Further, the results obtained from Eq. (10) differ by less than $13 \%$ from the results obtained by using other equations pertaining to fracture toughness.

The flexural strengths of the samples sintered at $1750^{\circ} \mathrm{C}$ increase from $251 \mathrm{MPa}$ for the nonadditive sample to 396 $\mathrm{MPa}$ for the sample containing $10 \mathrm{vol} \%$ nanoSiC, which cor- responds to an increase of $57 \%$. Moreover, the increase in temperature up to $1650^{\circ} \mathrm{C}$ contributes to the increase in the sintering capacity of the sample being more than the increase in the grain size. Therefore, the flexural strength of the sample is increased. However, with the increase in temperature up to $1700^{\circ} \mathrm{C}$, grain growth leads to a reduction in the flexural strength of the sample.

\section{REFERENCES}

1. D. W. Richerson, Modern Ceramic Engineering; $2^{\text {nd }}$ Edition, Marcel Dekker Inc., NewYork Basel; 1992.

2. C. A. Harper, Handbook of Materials for Product Materials for Product Design; $3^{\text {rd }}$ Edition, McGraw-Hill, London, 2001.

3. S. Sömiya, Handbook of Advanced Ceramics; Elsevier Academic Press, Oxford, 2003.

4. C. Kalkandelen, M. Suleymanoglu, S. E. Kuruca, A. Akan, F. N. Oktar, and O. Gunduz, "Part 2: Biocompatibility Evaluation of Hydroxyapatite-based Clinoptilolite and $\mathrm{Al}_{2} \mathrm{O}_{3}$ Composites," J. Aust. Ceram Soc., 53 [1] 217-23 (2017).

5. C. H. Huang and Y. Chen, "Effect of Mechanical Properties on the Ballistic Resistance Capability of $\mathrm{Al}_{2} \mathrm{O}_{3}-\mathrm{ZrO}_{2}$ Functionally Graded Materials," Ceram. Int., 42 [11] 12946-55 (2016).

6. Z. Aslanoglu and A. Sesver, "The Postmortem Study of Used Refractory Brick in EAF Dust Recovery Kiln," $J$. Aust. Ceram Soc., 53 [2] 933-38 (2017).

7. S. N. Monteiro, L. H. L. Louro, A. V. Gomes, C. F. M. Chagas, A. B. Caldeira, and E. P. Lima, "How Effective is a Convex $\mathrm{Al}_{2} \mathrm{O}_{3}-\mathrm{Nb}_{2} \mathrm{O}_{5}$ Ceramic Armor," Ceram. Int., 42 [6] 7844-47 (2016).

8. H. Setiawan, R. Khairani, M. A. Rahman, R. Septawendar, R. R. Mukti, H. K. Dipojono, and B. S. Purwasasmita, "Synthesis of Zeolite and Y-Alumina Nanoparticles as Ceramic Membranes for Desalination Applications," $J$. Aust. Ceram Soc., 53 [2] 531-38 (2017).

9. N. J. Welham and N. Setoudeh, "Formation of an Alumina-Silicon Carbide Nanocomposite," J. Mater. Sci., 40 [12] 3271-73 (2005).

10. H. Z. Wang, L. Gao, and J. K. Guo, "The Effect of Nanoscale $\mathrm{SiC}$ Particles on the Microstructure of $\mathrm{Al}_{2} \mathrm{O}_{3}$ Ceramics," Ceram. Int., 26 [4] 391-96 (2000).

11. A. Gadalla, M. Elmasry, and P. Kongkachuichay, "High

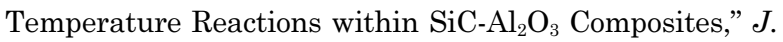
Mater. Res., 7 [9] 2585-92 (1992).

12. M. Parchovianský, J. Balko, P. Švančárek, J. Sedláček, J. Dusza, F. Lofaj, and D. Galusek, "Mechanical Properties and Sliding Wear Behaviour of $\mathrm{Al}_{2} \mathrm{O}_{3}$-SiC Nanocomposites with 3-20 vol\% SiC," J. Eur. Ceram Soc., 37 [14] 4297306 (2017).

13. C. Greskovich, and B. J. Anthony, "Solubility of Magnesia in Polycrystalline Alumina at High Temperatures," $J$. Am. Ceram. Soc., 84 [2] 420-25 (2004).

14. R. S. Mishra and A. K. Mukherjee, "Processing of High Hardness-High Toughness Alumina Matrix Nanocomposites," Mater. Sci. Eng. A, 301 [1] 97-101 (2001).

15. R. D. Bagley and D. L. Johnson, "Effect of Magnesia on 
Grain Growth in Alumina," Adv. Ceram., 10 666-78 (1984).

16. C. A. Duan, "Effects of Chemical in Homogeneities on Grain Growth and Microstructure in $\mathrm{Al}_{2} \mathrm{O}_{3}, " J$. Am. Ceram. Soc., 72 [1] 130-36 (1989).

17. J. Wang, S. Y. Lim, S. C. Ng, C. H. Chew, and L. M. Gan, "Dramatic Effect of a Small Amount of $\mathrm{MgO}$ Addition on the Sintering of $\mathrm{Al}_{2} \mathrm{O}_{3}-5 \mathrm{vol} \% \mathrm{SiC}$ Nanocomposite," Mater. Lett., 33 [5-6] 273-77 (1998).

18. M. Ahmadzadeh, H. Baharvandi, H. Abdizadeh, and A. M. Hadian, "Synthesis of Nano-Size MgO Powder by Chemical Deposition of Low Cost Raw Materials," Int. J. Mod. Phys. B, 22 [18] 3185-92 (2008).

19. ASTM B311-93, Test Method for Density Determination for Powder Metallurgy (P/M) Materials Containing Less Than Two Percent Porosity. Developed by Subcommittee: B09.11, Book of Standards: 02(05); 2002.

20. D. Galusek, J. Sedláček, P. Švančárek, R. Riedel, R. Satet, and M. Hoffmann, "The Influence of Post-Sintering HIP on the Microstructure, Hardness, and Indentation Fracture Toughness of Polymer-Derived $\mathrm{Al}_{2} \mathrm{O}_{3}-\mathrm{SiC}$ Nanocomposites," J. Eur. Ceram. Soc., 27 [2-3] 1237-45 (2007).

21. S. Sinhamahapatra, M. Shamim, H. S. Tripathi, A. Ghosh, and K. Dana, "Kinetic Modeling of Solid State Magnesium Aluminum at Espinel Formation and its Validation," Ceram. Int., 42 [7] 9204-13 (2016).

22. ASTM C1161-02c, Standard Test Method for Flexural Strength of Advanced Ceramics at Ambient Temperature. Developed by Subcommittee: C28.01, Book of Standards: 15(01); 2008.

23. ASTM C769-98, "Standard Test Method for Sonic Velocity in Manufactured Carbon and Graphite Materials for Use in Obtaining an Approximate Young's Modulus", Developed by Subcommittee: D02.F0, Book of Standards: 05(05); 2005.

24. ASTM C1327-08, Standard Test Method for Vickers Indentation Hardness of Advanced Ceramics", Developed by Subcommittee: C28.01, Book of Standards: 15(01); 2008.

25. A. Moradkhani, H. Baharvandi, M. Tajdari, H. Latifi, and J. Martikainen, "Determination of Fracture Toughness Using the Areas of Microcrack Tracks Left in Brittle Materials by Vickers Indentation Test," J. Adv. Ceram., 2 [1] 87-102 (2013).

26. K. A. Nihhara, R. Morena, and D. P. H. Hasselman, "Evaluation of KIC of Brittle Solids by the Indentation Method with Low Crack-to-Indent Ratios," J. Mater. Sci. Lett., 1 [1] 13-6 (1982).

27. D. K. Shetty, I. G. Wright, P. N. Mincer, and A. H. Cluar, "Indentation Fracture of WC-Co Cermets," J. Mater. Sci., 20 [5] 1873-82 (1985).

28. R. Gao, H. Wang, Q. Zhu, Q. Yang, X. Sun, B. Li, S. Xu, and X. Zhang, "The Forming Region and Mechanical Properties of $\mathrm{SiO}_{2}-\mathrm{Al}_{2} \mathrm{O}_{3}-\mathrm{MgO}$ Glasses," J. Non-Cryst. Solids, 470 132-37 (2017).

29. R. Mohammad-Rahimi, H. R. Rezaie, and A. Nemati, "Sintering of $\mathrm{Al}_{2} \mathrm{O}_{3}-\mathrm{SiC}$ Composite from Sol-Gel Method with $\mathrm{MgO}, \mathrm{TiO}_{2}$ and $\mathrm{Y}_{2} \mathrm{O}_{3}$ Addition," Ceram. Int., 37 [5]
1681-88 (2011)

30. A. R. Yazdi, H. Baharvandi, H. Abdizadeh, J. Purasad, A. Fathi, and H. Ahmadi, "Effect of Sintering Temperature and Siliconcarbide Fraction on Density, Mechanical Properties and Fracture mode of Alumina-Silicon Carbide Micro/Nanocomposites," Mater. Des., 37 251-55 (2012).

31. C. C. Anya and S. G. Roberts, "Pressureless Sintering and Elastic Constants of $\mathrm{A}_{2} \mathrm{O}_{3}$-SiC Nanocomposites," J. Eur. Ceram. Soc., 17 [4] 565-73 (1997).

32. E. Medvedovski, "Alumina-Mullite Ceramics for Structural Applications," Ceram. Int., 32 [4] 369-75 (2006).

33. A. Moradkhani and H. Baharvandi, "Microstructural Analysis of Fracture Surfaces and Determination of Mechanical Properties of $\mathrm{Al}_{2} \mathrm{O}_{3}-\mathrm{SiC}-\mathrm{MgO}$ Nanocomposites," Int. J. Refract. Met. Hard Mater., 67 40-55 (2017).

34. M. Sternitzke, "Review: Structural Ceramic Nanocomposites," J. Eur. Ceram. Soc., 17 [9] 1061-82 (1997).

35. L. Xuefei, L. Hanlian, H. Chuanzhen, Z. Bin, and Z. Longwei, "High Temperature Mechanical Properties of $\mathrm{Al}_{2} \mathrm{O}_{3}$ based Ceramic Tool Material Toughened by SiC Whiskers and Nanoparticles," Ceram. Int., 43 [1] 1160-65 (2017).

36. J. F. Shackelford and W. Alexander, CRC Materials Science and Engineering Handbook; $3^{\text {rd }}$ Edition, CRC Press, Florida, 2001.

37. A. Moradkhani, H. Baharvandi, and M. M. M. Samani, "Mechanical Properties and Microstructure of B4C-Nano$\mathrm{TiB}_{2}-\mathrm{Fe} / \mathrm{Ni}$ Composites under Different Sintering Temperatures," Mater. Sci. Eng. A, 665 141-53 (2016).

38. A. Moradkhani and H. Baharvandi, "Analyzing the Microstructures of W-ZrC Composites Fabricated through Reaction Sintering and Determining their Fracture Toughness Values by Using the SENB and VIF Methods," Eng. Fract. Mech., 189 501-13 (2018).

39. A. Moradkhani and H. Baharvandi, "Effects of Additive Amount, Testing Method, Fabrication Process and Sintering Temperature on the Mechanical Properties of $\mathrm{Al}_{2} \mathrm{O}_{3} / 3 \mathrm{Y}$ TZP Composites," Eng. Fract. Mech., 191 446-60 (2017).

40. A. Moradkhani, H. Baharvandi, and A. Naserifar, "Fracture Toughness of 3Y-TZP Dental Ceramics by Using Vickers Indentation Fracture and SELNB Methods," J. Korean Ceram. Soc., 56 [1] 37-48 (2019).

41. B. K. Jang, M. Enoki, T. Kishi, H. K. Oh, "Effect of Second Phase on Mechanical Properties and Toughening of $\mathrm{Al}_{2} \mathrm{O}_{3}$ based Ceramic Composites," Comps. Eng., 5 [10-11] 1275-86 (1995).

42. J. Zhao, L. C. Stearns, M. P. Harmer, H. M. Chan, G. A. Miller, and R. F. Cook, "Mechanical Behavior of AluminaSilicon Carbide Nanocomposites," J. Am. Ceram. Soc., 76 [2] 503-10 (1993).

43. T. Ohji, Y. K. Jeong, Y. H. Choa, and K. Niihara, "Strengthening and Toughening Mechanisms of Ceramic Nanocomposites," J. Am. Ceram. Soc., 81 [6] 1453-60 (1998).

44. I. Levin, W. D. Kaplan, D. G. Brandon, and A. A. Layyous, "Effect of SiC Submicrometer Particle Size and Content on Fracture Toughness of Alumina-SiC Nanocomposites," J. Am. Ceram. Soc., 78 [1] 254-56 (1995). 